\title{
Patterns of Psychiatric Outpatient Practice in Taiwan: A Nationwide Survey
}

\author{
Ying-Xiu Dai ${ }^{1,2}$, Mu-Hong Chen ${ }^{2,3}$, Tzeng-Ji Chen ${ }^{1,2}$ and Ming-Hwai Lin ${ }^{1,2, *}$ \\ 1 Department of Family Medicine, Taipei Veterans General Hospital, No. 201, Sec. 2, Shi-Pai Road, \\ Taipei 112, Taiwan; daiinxiu@gmail.com (Y.-X.D.); tjchen@vghtpe.gov.tw (T.-J.C.) \\ 2 School of Medicine, National Yang-Ming University, No. 155, Sec. 2, Linong Street, Taipei 112, Taiwan; \\ kremer7119@gmail.com \\ 3 Department of Psychiatry, Taipei Veterans General Hospital, No. 201, Sec. 2, Shi-Pai Road, Taipei 112, Taiwan \\ * Correspondence: minghwai@gmail.com; Tel.: +886-2-28757458
}

Academic Editor: Icro Maremmani

Received: 10 July 2016; Accepted: 23 September 2016; Published: 28 September 2016

\begin{abstract}
Background: Limited studies have utilized nationwide data to assess the patterns of psychiatric practice in other countries. In this study, data from the National Health Insurance Research Database in Taiwan (NHIRD-TW) for 2012 was analyzed to determine the patterns of psychiatric outpatient practice in Taiwan; (2) Methods: To determine the patterns of psychiatric outpatient practice in Taiwan, the data were drawn from the datasets of Taiwan's National Health Insurance Research Database for 2012, with 619,760 records of outpatient visits representing 1/500 of all the claims in Taiwan for that year. The analysis of psychiatric outpatient visits included patient demographics, diagnoses, and prescribed medications; (3) Results: Neurotic disorders were the most prevalent diagnoses $(43.1 \%, \mathrm{n}=5714)$. Hypnotics-sedatives and anxiolytics were prescribed in $51.7 \%$ $(\mathrm{n}=6850)$ and $39.1 \%(\mathrm{n}=5181)$ of psychiatric visits, respectively, with zolpidem being the most commonly prescribed drug $(22.6 \%, \mathrm{n}=2998)$; and (4) Conclusion: Hypnotics and sedatives were widely prescribed for the outpatient population, and zolpidem had the highest annual prevalence of use. These findings deserve the attention of clinicians and policy makers for monitoring the abuse and dependence of these agents and subsequent adverse events.
\end{abstract}

Keywords: national health programs; physician's practice patterns; psychiatry; Taiwan

\section{Introduction}

With ongoing innovations in psychotropic medications, advances in rehabilitation models, and reforms to health care insurance systems, psychiatric practice has changed substantially in recent years. Comprehensive and detailed information is necessary in order to better understand and improve upon psychiatric services. Previous pharmacoepidemiological studies have analyzed the use of psychotropic drugs in various nationwide populations [1-3]. Many studies have also investigated the epidemiology of psychiatric visits to emergency departments [4-7]. Some reports have reviewed the trends and patterns of office-based psychiatric care in the United States based on the National Ambulatory Medical Care Survey, the National Hospital Ambulatory Medical Care Survey, and the National Health and Nutrition Examination Survey [8-10]. However, studies utilizing nationwide data to assess the patterns of psychiatric practice in other countries are limited. The Taiwan National Health Insurance (NHI) program was established in 1995 to provide health care to all residents in Taiwan. Currently, $99.9 \%$ of Taiwan's population is covered by the NHI program. It is a government-administered insurance-based national healthcare system. Taiwan has a single payer system for healthcare. The characteristics of the NHI system include good accessibility, comprehensive population coverage, short waiting times, relatively low costs, and a national health insurance databank 
for planning, monitoring, and evaluating health services. However, the gatekeeper role of family doctors is weak in Taiwan. Taiwanese people are able to choose their healthcare providers freely, including any specialty and level of medical service. The National Health Insurance Administration of the Ministry of Health and Welfare has released all de-identified claims data dating back to 1999 for academic research. The National Health Insurance Research Database in Taiwan (NHIRD-TW) contains the original medical claims data submitted by all service providers in the nation. In this study, data from the NHIRD-TW for 2012 was analyzed to determine the patterns of psychiatric outpatient practice in Taiwan.

\section{Materials and Methods}

\subsection{Data Collection}

We assessed the files sampled from those of the year 2012 (S_CD20120.DAT and S_OO20120.DAT of NHIRD). The dataset "CD" means collection of all the outpatient visit files; on the other hand, the dataset "OO" refers to the outpatient order files. These two collections of files-containing a total of 619,760 medical records-were acquired by a $0.2 \%$ sampling ratio from the $\mathrm{CD}$ and $\mathrm{OO}$ datasets for 2012, excluding dentistry and traditional Chinese medicine. In this study, the data of outpatient visits encompassed visits to psychiatrists in outpatient departments of general hospitals, mental health hospitals, and physician clinics. It also included services from daycare wards and community rehabilitation centers, while the data of inpatient claims were not included in the study. All the diagnosis codes in every medical record were analyzed and demonstrated in the distribution of diagnoses among psychiatric outpatients, including psychiatric and nonpsychiatric diagnoses (Table 1).

Table 1. The distribution of diagnoses among psychiatric outpatients with all diagnoses at each claim were taken into account.

\begin{tabular}{cccc}
\hline ICD9CM & Diagnosis Group & (n = 13,261) & \% \\
\hline 300 & Neurotic disorders & 5714 & 43.1 \\
296 & Affective psychoses & 3244 & 24.5 \\
295 & Schizophrenic disorders & 2359 & 17.8 \\
307 & General symptoms & 2327 & 17.5 \\
780 & Special symptoms or syndromes, not elsewhere classified & 1299 & 9.8 \\
311 & Depressive disorder, not elsewhere classified & 733 & 6.1 \\
564 & Functional digestive disorders, not elsewhere classified & 693 & 5.2 \\
290 & Senile and presenile organic psychotic conditions & 667 & 5.0 \\
314 & Hyperkinetic syndrome of childhood & 518 & 3.9 \\
294 & Other organic psychotic conditions (chronic) & 516 & 3.9 \\
401 & Essential hypertension & 431 & 3.3 \\
309 & Adjustment reaction & 263 & 2.0 \\
333 & Other extrapyramidal disease and abnormal movement disorders & 238 & 1.8 \\
784 & Symptoms involving head and neck & 209 & 1.6 \\
250 & Diabetes mellitus &
\end{tabular}

ICD9CM: International Classification of Diseases, 9th Revision, Clinical Modification.

\subsection{Study Population}

Analysis was conducted on the datasets of outpatient visit files and outpatient order files sampled from the NHIRD-TW for 2012. The sampled dataset contained 13,261 records, representing 1/500 of all the claims for outpatient services in 2012. Disease categories based on the International Classification of Diseases, 9th Revision, Clinical Modification (ICD-9-CM) classification were used to analyze the diagnoses in the outpatient visits. The Anatomical Therapeutic Chemical (ATC) classification system was used to assess prescription patterns. Outpatient visits were stratified by patient gender, age, diagnoses, and medications. The patterns of nonpharmacological treatments were also examined. 


\subsection{Statistical Analysis}

The data were analyzed using the programming software Perl version 5.20.2 (Perl, Walnut, CA, USA) for data processing and using the statistical software SPSS version 22.0 (IBM, Armonk, NY, USA) for statistical analysis. Pearson's $\chi^{2}$ test was used for group comparisons. A $p$-value $<0.05$ (two-tailed) was considered statistically significant. The study was approved by institutional review board of Taipei Veterans General Hospital according to the Republic of China law (VGHIRB No.: 2013-10-001CE).

\section{Results}

\subsection{The Demographics of Psychiatric Outpatients}

We identified 13,261 psychiatric outpatient visits, which accounted for $2.1 \%$ of all ambulatory care visits $(n=619,760)$ in 2012. Of the psychiatric outpatient visits, 7159 visits $(54.0 \%)$ were made by female patients, and 6203 visits $(46.0 \%)$ were made by male patients. In terms of age, patients aged $30-39$ years $(17.0 \%), 40-49$ years $(21.0 \%)$, and $50-59$ years $(20.2 \%)$ comprised the majority of the outpatients in 2012 (Figure 1). A predominance of male patients in the psychiatric outpatient visits was found among patients aged 0-9 and 10-19, with male-to-female ratios of 3.47 and 2.07, respectively, while male-to-female ratios ranging between 0.73 and 0.93 were observed in patients aged 20 and older.

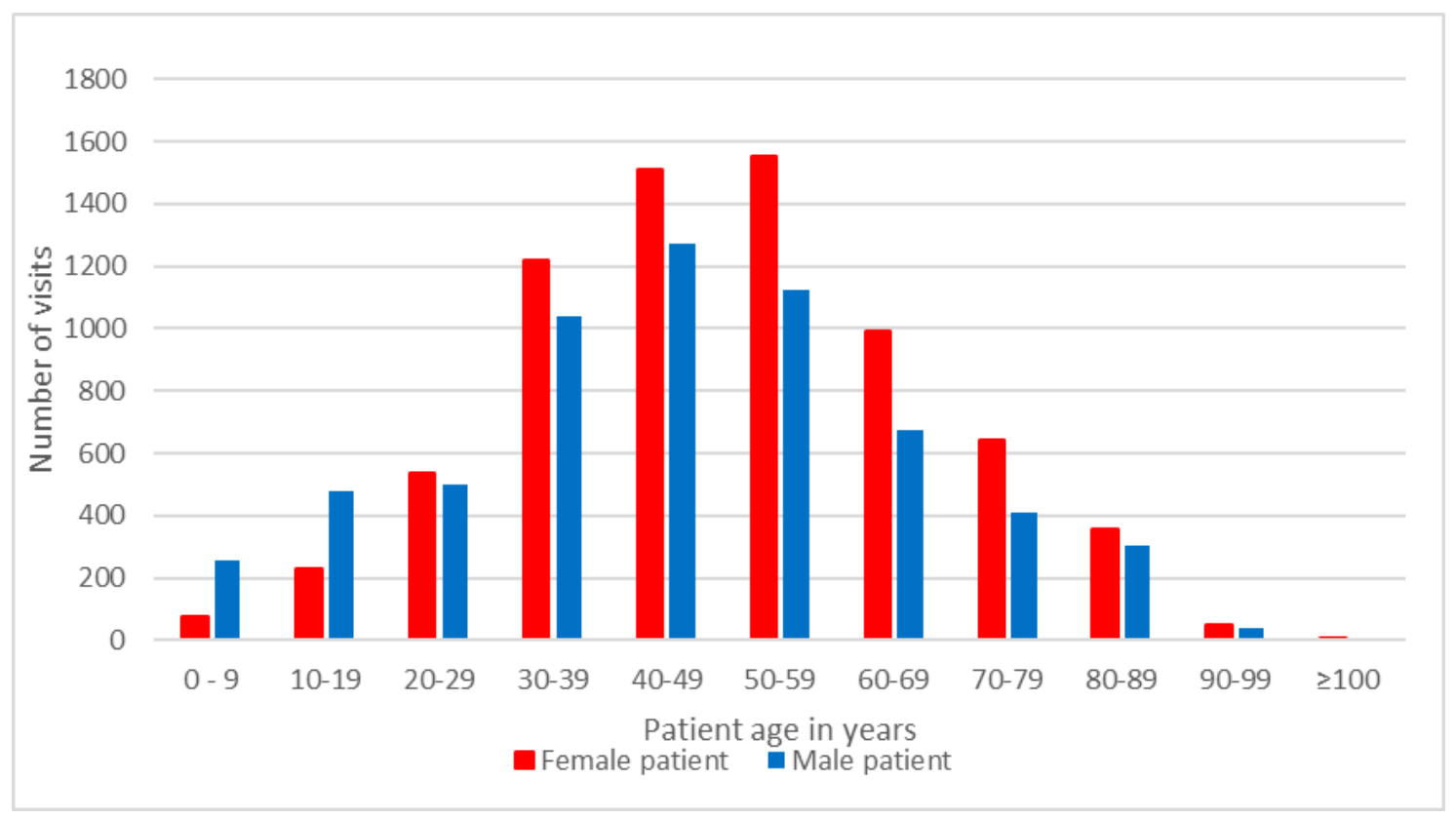

Figure 1. Number of outpatients visits by patient age and gender.

\subsection{Distribution of Outpatient Visits by Patient's Diagnosis}

Table 1 shows the distribution of diagnoses among psychiatric outpatients with all diagnoses at each claim taken into account. Diagnoses of mental disorders were found for $98.0 \%(n=12,998)$ of psychiatric outpatient visits. In terms of the first diagnosis code listed in the medical claims, neurotic disorders $(\mathrm{n}=4281,32.3 \%)$, affective disorders $(\mathrm{n}=2854,21.5 \%)$, and schizophrenic disorders ( $n=2241,16.9 \%$ ) were the major diagnoses at all facility levels. Among visits to physician clinics $(n=4379), 50.2 \%(n=2198)$ of the first diagnosis codes were neurotic disorders. Neurotic disorders (ICD-9-CM diagnosis code 300) correspond to dysthymic disorder, anxiety disorders, obsessive-compulsive disorders, somatoform disorders, dissociative disorders, and factitious disorders in the Diagnostic and Statistical Manual of Mental Disorders (DSM) classification system. Considering the diagnostic distribution in terms of patient gender, there were more female patients $(n=2594,60.6 \%)$ 
than male patients $(n=1687,39.4 \%)$ among the patients with neurotic disorders $(n=4281)$. Among the patients with affective disorders $(n=2854)$, male patients accounted for $37.3 \%(n=1064)$ and female patients accounted for $62.7 \%(\mathrm{n}=1790)$ of outpatient visits. Among the patients with schizophrenic disorders $(\mathrm{n}=2241), 53.4 \%(\mathrm{n}=1196)$ of the visits were made by male patients, while $46.6 \%(n=1045)$ were made by female patients. Constipation, hypertension, and diabetes mellitus were the most common medical diagnoses among the psychiatric outpatients. In patients with constipation, affective disorders $(29.3 \%)$ were the most prevalent diagnoses, followed by schizophrenic disorders $(28.8 \%)$ and neurotic disorders $(23.7 \%)$. Among patients with diabetes mellitus, schizophrenic disorders $(38.8 \%)$ were far more prevalent than affective disorders $(20.1 \%)$ and neurotic disorders $(10.5 \%)$.

\subsection{Distribution of Outpatient Visits by Pharmacological and Nonpharmacological Treatments}

As shown in Table 2, among nonpharmacological treatments, supportive psychotherapy was the most commonly applied treatment, followed by individual re-educative psychotherapy. Other infrequently performed treatments included behavioral therapy, supportive group psychotherapy, re-educative group psychotherapy, activity therapy, biofeedback therapy, and occupational therapy. With regard to patient gender, supportive psychotherapy was applied to $983(46.4 \%)$ male patients and $1134(53.6 \%)$ female patients. More female patients $(n=937,59.4 \%)$ than male patients $(n=641,40.6 \%)$ received re-educative group psychotherapy.

Table 2. Numbers and percent distributions of nonpharmacological treatments.

\begin{tabular}{cccc}
\hline NHI Code & Treatment & (n = 13,261) & $\mathbf{\%}$ \\
\hline 45010C & Supportive individual psychotherapy & 2117 & 16.0 \\
45087C & Re-educative individual psychotherapy-adult & 1578 & 11.9 \\
45088C & Re-educative individual psychotherapy: 6-15 years old & 127 & 1.0 \\
45100C & Behavior modification assessment & 49 & 0.4 \\
45013C & Intensive individual psychotherapy-adult & 34 & 0.3 \\
45016C & Supportive group psychotherapy & 33 & 0.2 \\
45094C & Re-educative group psychotherapy & 24 & 0.2 \\
4502CC & Activity therapy (day) & 24 & 0.2 \\
45043C & Biofeedback therapy & 14 & 0.1 \\
45089C & Re-educative individual psychotherapy-under 6 years old & 12 & 0.1 \\
45095C & Special Occupational therapy & 0.1 \\
45090C & Intensive individual psychotherapy: 6-15 years old & 7 & 0.1 \\
\hline
\end{tabular}

NHI: national health insurance.

In terms of pharmacological treatments, $92.6 \%(n=12,279)$ of outpatients were managed with medications, and $56.3 \%(n=7475)$ of outpatients received three or more medications. Among visits without the use of medications $(\mathrm{n}=982)$, male patients accounted for $60.4 \%$ of the visits, and schizophrenic disorders were the most prevalent diagnoses $(16.6 \%)$. In terms of patients' diagnosis, $57.2 \%(n=3266)$ of patients with neurotic disorders, $64.0 \%(n=1510)$ of patients with schizophrenic disorders, and $74.2 \%(\mathrm{n}=2406)$ patients with affective disorders were managed with three or more medications. A higher proportion of female patients with neurotic disorders $(59.8 \%, \mathrm{n}=1983)$ than male patients $(56.9 \%, \mathrm{n}=1283)$ received three or more medications. In patients with schizophrenic disorders and affective disorders, the use of three or more medications were seen in $71.7 \%$ of females vs. $70.8 \%$ of males and $77.3 \%$ of females vs. $76.7 \%$ of males, respectively.

As shown in Table 3, the most commonly prescribed drugs were hypnotics and sedatives, followed by antidepressants, anxiolytics, antipsychotics, and antiepileptics. There were more female patients $(\mathrm{n}=7029,58.4 \%)$ than male patients $(\mathrm{n}=5002,41.6 \%)$ who received hypnotics-sedatives and anxiolytics $(n=12,031)$. In patients with affective disorders and neurotic disorders, antidepressants were the most common medications, while antipsychotics were the most common medications in patients with schizophrenic disorders. 
Table 3. The prescription of drugs by Anatomical Therapeutic Chemical (ATC) 3rd level.

\begin{tabular}{cccc}
\hline ATC Code & Drug Classification & $\mathbf{n = 1 3 , 2 6 1}$ & $\mathbf{\%}$ \\
\hline N05C & Hypnotics and sedatives & 6850 & 51.7 \\
N06A & Antidepressants & 6461 & 48.7 \\
N05B & Anxiolytics & 5181 & 39.1 \\
N05A & Antipsychotics & 4869 & 36.7 \\
N03A & Antiepileptics & 3076 & 23.2 \\
C07A & Beta blocking agents & 1443 & 10.9 \\
N04A & Anticholinergic agents & 1410 & 10.6 \\
A06A & Laxatives & 812 & 6.1 \\
N06B & Pscyhostimulants & 671 & 5.1 \\
N06C & Psycholeptics and psychoanaleptics in combination & 578 & 4.4 \\
\hline
\end{tabular}

On the ATC 5th level, zolpidem was the most commonly prescribed psychotropic drug, followed by clonazepam, alprazolam, lorazepam, trazodone, estazolam, and quetiapine (Table 4). Of the patients receiving zolpidem, $62.0 \%$ were female $(n=1862)$. Zolpidem was most commonly prescribed in physician clinics $(n=1320,44.0 \%)$, followed by metropolitan hospitals $(n=810,27.0 \%)$, academic medical centers $(n=466,15.5 \%)$, and local community hospitals $(n=402,13.4 \%)$.

Table 4. The prescription of drugs by ATC 5th level.

\begin{tabular}{cccc}
\hline ATC Code & Drug Classification & $\mathbf{n = 1 3 , 2 6 1}$ & $\mathbf{\%}$ \\
\hline N05CF02 & Zolpidem & 2998 & 22.6 \\
N03AE01 & Clonazepam & 2312 & 17.4 \\
N05BA12 & Alprazolam & 2222 & 16.8 \\
N05BA06 & Lorazepam & 1894 & 14.3 \\
N06AX05 & Trazodone & 1675 & 12.6 \\
N05CD04 & Estazolam & 1583 & 11.9 \\
N05AH04 & Quetiapine & 1352 & 10.2 \\
C07AA05 & Propranolol & 1331 & 10.0 \\
N05CD03 & Flunitrazepam & 1102 & 8.3 \\
N06AB10 & Escitalopram & 1089 & 8.2 \\
\hline
\end{tabular}

Trazodone was the most popular antidepressant, probably because it was usually used as a hypnotic in Taiwan. Other antidepressants included escitalopram, sertraline, mirtazapine, paroxetine, melitracen, fluoxetine, venlafaxine, citalopram, duloxetine, moclobemide, and milnacipran. Selective serotonin reuptake inhibitors $(25.6 \%)$ were prescribed more frequently than serotonin norepinephrine reuptake inhibitors $(6.3 \%)$ and other antidepressants. Among patients receiving antidepressants, $60.0 \%$ $(\mathrm{n}=3876)$ were female and $40.0 \%(\mathrm{n}=2585)$ were male.

Quetiapine was the most commonly used antipsychotic, followed by risperidone, sulpiride, olanzapine, aripiprazole, haloperidol, clozapine, amisulpride, flupentixol, chlorpromazine, clotiapine, zotepine, paliperidone, trifluoperazine, ziprasidone, thioridazine, zuclopenthixol, and fluphenazine. Second-generation antipsychotics were more commonly prescribed than first-generation antipsychotics ( $28.3 \%$ vs. $11.6 \%)$.

Among mood stabilizers, valproic acid was the most commonly prescribed drug, followed by lithium, lamotrigine, and carbamazepine.

Laxatives were the most commonly used non-psychotropic drugs, including senna glycoside, magnesium oxide, and bisacodyl.

\section{Discussion}

In 2012, psychiatric outpatient visits accounted for $2.1 \%$ of all ambulatory care visits in Taiwan, which was relatively low compared with $3.1 \%$ in the United States [11]. Previous studies showed that 
the use of outpatient mental health services is associated with the prevalence of mental morbidity and the perceived need for care [12]. The lower proportion of psychiatric outpatient visits among all ambulatory care in Taiwan requires further investigation. The present study found that more outpatient psychiatric visits were made by females than males ( $54.0 \%$ vs. $46.0 \%$ ). A previous study also demonstrated that females use mental health care services more frequently than males [13], but this pattern depends on the type and severity of mental health problems [14]. Taking only the first diagnosis for each claim into account, there were more female patients than male patients among the patients with neurotic disorders $(60.1 \%$ vs. $39.9 \%)$ and among those with affective disorders $(62.7 \%$ vs. $37.3 \%)$. These findings were consistent with prior epidemiological studies that found a higher risk of mental disorders—especially neurotic disorders and affective disorders [15]—among females than among males, with those types of disorders being the most prevalent diagnoses among psychiatric outpatients. Patients under the age of $60(73.8 \%)$ were the major source of outpatients. This might have been due to the higher prevalence of mental illness among young adults than among older adults [16,17].

In roughly half of outpatient visits $(51.7 \%)$, hypnotics and sedatives were prescribed. Among those drugs, zolpidem was the most commonly prescribed (22.6\%). Compared with male patients, female patients were more commonly prescribed with hypnotics-sedatives and anxiolytics, including zolpidem. Higher rates for the usage of hypnotics among female patients have been demonstrated in previous studies [18], and may be partially explained by higher prevalences of affective disorders, anxiety disorders, and insomnia among female patients $[15,19]$. In addition, the most common comorbidities associated with insomnia are psychiatric disorders $[20,21]$. It has been reported that $40 \%$ of patients with insomnia have coexisting psychiatric disorders [22]. Depression is the most common comorbidity among these psychiatric disorders [23]. Insomnia comorbid with psychiatric disorders, medical disorders, or substance use accounts for $85 \%-90 \%$ of chronic insomnia [24].

High rates of benzodiazepine and Z-drug usage in Taiwan have been reported in the prior literature. Wang et al. reported an annual prevalence of anxiolytic-hypnotic use of more than $20 \%$ in Taiwan. Furthermore, the greatest increases in use between 2002 and 2009 were seen for the drugs clonazepam and zolpidem, which, in our study, were the two most commonly prescribed medications for the psychiatric outpatient population. The annual prevalence of zolpidem use in Taiwan increased from $2.4 \%$ in 2002 to $4.2 \%$ in 2009 [25]. The relatively higher prevalence of hypnotic use in this study might be explained by the fact that most psychiatric outpatients had psychiatric disorders, including neurotic disorders and affective disorders. Previous studies have shown that long-term use of benzodiazepines is associated with increased risk of adverse effects [26], increased risk of accidents such as falling [27,28], and increased cognitive decline in the elderly [29]. Zolpidem has been considered safer than benzodiazepines, and it is associated with a lower probability of abuse and dependence [30]. However, there is a growing evidence that zolpidem has the potential for abuse and dependence [31,32]. The finding of high prevalence of hypnotics and sedatives use poses significant concerns regarding dependence on these agents and subsequent adverse events. Clinicians should reduce unnecessary use of hypnotics and sedatives and monitor their risk of dependence carefully. Notably, recent studies found that zolpidem is associated with increased risk of motor vehicle collisions $[33,34]$. Considering the high prevalence of zolpidem use in psychiatric outpatients, clinicians should consider nonpharmacological treatment before initiating zolpidem in this population.

As the most prevalent antidepressant, trazodone was more commonly used as a hypnotic in Taiwan. However, the evidence supporting the use of trazodone as a hypnotic is limited [35,36]. The high prevalence of trazodone use as a hypnotic in Taiwan thus deserves further study to evaluate the underlying causes and potential risks. The trends in the prescription of atypical antipsychotics and the new generation of antidepressants were demonstrated in this study. In 2002, typical antipsychotics were more commonly prescribed than atypical antipsychotics (12\% vs. $0.7 \%$ ) [37], while in 2012 , the rate of prescriptions for atypical antipsychotics was more than two times that of typical antipsychotics $(27.4 \%$ vs. $11.6 \%)$. The trend of atypical antipsychotics taking the place of typical antipsychotics has also been reported in other countries [38,39]. Although the atypical antipsychotics have some 
advantages over typical antipsychotics (such as causing extrapyramidal syndromes less frequently), the increased risk of metabolic effects, including diabetes, hyperlipidemia, and obesity associated with atypical antipsychotics warrants clinical attention [40]. While the rate of prescriptions for non-selective monoamine reuptake inhibitors exceeded that of prescriptions for selective serotonin reuptake inhibitors $(3.3 \%$ vs. $1.8 \%$ ) in 2002 , selective serotonin reuptake inhibitors $(55.1 \%)$ were the most prevalent antidepressants as of 2012. A similar phenomenon was also previously documented in the United States [41]. While lithium was the most prevalent mood stabilizer in 2002 (4\%), valproic acid had surpassed lithium as of $2012(6.1 \%$ vs. $2.0 \%)$ [37]. These changes in mood stabilizer usage rates might be explained by the changing clinical practice in the treatment of bipolar disorders. Trends of increased use of anticonvulsants and decreased use of lithium in the treatment of acute mania in German, Swiss, and Austrian hospitals between 1994 and 2004 were also reported [42]. Although lithium retains a role as a first-line treatment of acute mania, it has narrow therapeutic index and many side effects, including tremor, polydipsia, polyuria, and, in the long term, hypothyroidism [43]. While valproic acid has grown in popularity, prescribers should carefully monitor its side effects, such as teratogenicity, weight gain, hair loss, and hepatotoxicity [44].

The common medical comorbidities among psychiatric outpatients included constipation, hypertension, and diabetes mellitus. It has previously been demonstrated that people with severe mental illnesses have a higher risk of diabetes and hypertension [45-47]. In this study, the diagnosis of constipation was found in $5.5 \%$ of psychiatric outpatients. The common use of laxatives was reflected by the high prevalence of constipation in our data. Psychotropic drugs and psychiatric comorbidities might be associated with the occurrence of constipation $[48,49]$. Antipsychotics, tricyclic antidepressants, and selective serotonin reuptake inhibitors have been reported to be associated with increased risk of constipation [48].

There were some limits to this study. First, this was a cross-sectional study. The changes and potential trends across time could not be identified due to the lack of longitudinal data. Second, the associations between various mental illnesses and comorbidities were not investigated due to the sampling methods used in this study. Third, the patterns of prescriptions for different diagnoses were not examined. Fourth, data regarding the services provided by general physicians and nonpsychiatrist specialists were not included in this study. Wang et al. previously demonstrated a higher proportion of inadequate psychiatric treatment in general medical sectors than in the mental health specialty [50]. The lack of such data in this study limits the degree to which psychiatric practices for outpatient populations can be assessed accurately. Fifth, prescription information may be under-reported, because the ambulatory data did not include prescription drugs from pharmacies. Sixth, due to the study design, this study focused on the basic features of psychiatric outpatient visits, it being inappropriate to analyze the association between the variables. Finally, the diagnoses listed in the medical claims in the insurance system might not accurately represent patients' true conditions, and their validity was rarely examined.

\section{Conclusions}

This nationwide population-based study characterized psychiatric outpatient practice in Taiwan. Hypnotics-sedatives and anxiolytics were found to be widely prescribed, especially zolpidem. Further research and policy interventions are necessary to explore the potential abuse of hypnotics-sedatives and anxiolytics in the outpatient population.

Acknowledgments: This study was partially supported by grants from Ministry of Science and Technology, R.O.C. (MOST 104-2410-H-010-015) and Taipei Veterans General Hospital (V105E10-002-MY2-1).

Author Contributions: Ming-Hwai Lin designed the study; Ying-Xiu Dai, Mu-Hong Chen, and Ming-Hwai Lin conducted the research; Ying-Xiu Dai and Tzeng-Ji Chen analyzed the data; Ying-Xiu Dai and Mu-Hong Chen wrote the manuscript; Ming-Hwai Lin was primarily responsible for the final content; All authors read and approved the final manuscript.

Conflicts of Interest: The authors declare no conflict of interest. 


\section{References}

1. Hermann, R.C.; Yang, D.; Ettner, S.L.; Marcus, S.C.; Yoon, C.; Abraham, M. Prescription of antipsychotic drugs by office-based physicians in the United States, 1989-1997. Psychiatr. Serv. 2002, 53, 425-430. [CrossRef] [PubMed]

2. Chien, I.C.; Bih, S.H.; Chou, Y.J.; Lin, C.H.; Lee, W.G.; Chou, P. Trends in the use of psychotropic drugs in Taiwan: A population-based national health insurance study, 1997-2004. Psychiatr. Serv. 2007, 58, 554-557. [CrossRef] [PubMed]

3. Wu, C.S.; Shau, W.Y.; Chan, H.Y.; Lee, Y.C.; Lai, Y.J.; Lai, M.S. Utilization of antidepressants in Taiwan: A nationwide population-based survey from 2000 to 2009. Pharmacoepidemiol. Drug Saf. 2012, 21, 980-988. [CrossRef] [PubMed]

4. Hazlett, S.B.; McCarthy, M.L.; Londner, M.S.; Onyike, C.U. Epidemiology of adult psychiatric visits to U.S. emergency departments. Acad. Emerg. Med. 2004, 11, 193-195. [CrossRef] [PubMed]

5. Larkin, G.L.; Claassen, C.A.; Emond, J.A. Trends in U.S. emergency department visits for mental health conditions, 1992 to 2001. Psychiatr. Serv. 2005, 56, 671-677. [CrossRef] [PubMed]

6. Kunen, S.; Prejean, C.; Gladney, B. Disposition of emergency department patients with psychiatric comorbidity: Results from the 2004 National Hospital Ambulatory Medical Care Survey. Emerg. Med. J. 2006, 23, 274-275. [CrossRef] [PubMed]

7. Sankaranarayanan, J.; Puumala, S.E. Epidemiology and characteristics of emergency departments visits by U.S. adults with psychiatric disorder and antipsychotic mention from 2000 to 2004. Curr. Med. Res. Opin. 2007, 23, 1375-1385. [CrossRef] [PubMed]

8. CDC Morbidity and Mortality Weekly Report-Mental Illness Surveillance among Adults in the United States. Available online: http://www.cdc.gov/mmwr/preview/mmwrhtml/su6003a1.htm (accessed on 6 July 2016).

9. Olfson, M.; Blanco, C.; Wang, S.; Laje, G.; Correll, C.U. National trends in the mental health care of children, adolescents, and adults by office-based physicians. JAMA Psychiatry 2014, 71, 81-90. [CrossRef] [PubMed]

10. Olfson, M.; Kroenke, K.; Wang, S.; Blanco, C. Trends in office-based mental health care provided by psychiatrists and primary care physicians. J. Clin. Psychiatry 2014, 75, 247-253. [CrossRef] [PubMed]

11. CDC Nonresponse Bias in Estimates from the 2012 National Ambulatory Medical Care Survey. Available online: http://www.cdc.gov/nchs/data/series/sr_02/sr02_171.pdf (accessed on 6 July 2016).

12. Katz, S.J.; Kessler, R.C.; Frank, R.G.; Leaf, P.; Lin, E.; Edlund, M. The use of outpatient mental health services in the United States and Ontario: The impact of mental morbidity and perceived need for care. Am. J. Public Health 1997, 87, 1136-1143. [CrossRef] [PubMed]

13. Matheson, F.I.; Smith, K.L.; Fazli, G.S.; Moineddin, R.; Dunn, J.R.; Glazier, R.H. Physical health and gender as risk factors for usage of services for mental illness. J. Epidemiol. Community Health 2014, 68, 971-978. [CrossRef] [PubMed]

14. Kovess-Masfety, V.; Boyd, A.; van de Velde, S.; de Graaf, R.; Vilagut, G.; Haro, J.M.; Florescu, S.; O’Neill, S.; Weinberg, L.; Alonso, J.; EU-WMH investigators. Are there gender differences in service use for mental disorders across countries in the European Union? Results from the EU-World Mental Health survey. J. Epidemiol. Community Health 2014, 68, 649-656.

15. Seedat, S.; Scott, K.M.; Angermeyer, M.C.; Berglund, P.; Bromet, E.J.; Brugha, T.S.; Demyttenaere, K.; de Girolamo, G.; Haro, J.M.; Jin, R.; et al. Cross-national associations between gender and mental disorders in the World Health Organization World Mental Health Surveys. Arch. Gen. Psychiatry 2009, 66, 785-795. [CrossRef] [PubMed]

16. Kessler, R.C.; Berglund, P.; Demler, O.; Jin, R.; Merikangas, K.R.; Walters, E.E. Lifetime prevalence and age-of-onset distributions of DSM-IV disorders in the National Comorbidity Survey Replication. Arch. Gen. Psychiatry 2005, 62, 593-602. [CrossRef] [PubMed]

17. Kessler, R.C.; Chiu, W.T.; Demler, O.; Merikangas, K.R.; Walters, E.E. Prevalence, severity, and comorbidity of 12-month DSM-IV disorders in the National Comorbidity Survey Replication. Arch. Gen. Psychiatry 2005, 62, 617-627. [CrossRef] [PubMed]

18. Bertisch, S.M.; Herzig, S.J.; Winkelman, J.W.; Buettner, C. National Use of Prescription Medications for Insomnia: NHANES 1999-2010. Sleep 2014, 29, 85-93. [CrossRef] [PubMed]

19. Zhang, B.; Wing, Y.K. Sex differences in insomnia: A meta-analysis. Sleep 2006, 29, 85-93. [PubMed] 
20. Ford, D.E.; Kamerow, D.B. Epidemiologic study of sleep disturbances and psychiatric disorders. An opportunity for prevention? JAMA 1989, 262, 1479-1484. [CrossRef] [PubMed]

21. Katz, D.A.; McHorney, C.A. Clinical correlates of insomnia in patients with chronic illness. Arch. Intern. Med. 1998, 158, 1099-1107. [CrossRef] [PubMed]

22. McCall, W.V. A psychiatric perspective on insomnia. J. Clin. Psychiatry 2001, 62, 27-32.

23. Ancoli-Israel, S. The impact and prevalence of chronic insomnia and other sleep disturbances associated with chronic illness. Am. J. Manag. Care 2006, 12, 221-229.

24. Ohayon, M.M. Epidemiology of insomnia: What we know and what we still need to learn. Sleep Med. Rev. 2002, 6, 97-111. [CrossRef] [PubMed]

25. Wang, L.J.; Chen, Y.C.; Chen, C.K.; Chou, W.J.; Chou, M.C. Trends in anxiolytic-hypnotic use and polypharmacy in Taiwan, 2002-2009: A nationwide, population-based survey. Psychiatr. Serv. 2014, 65, 208-214. [CrossRef] [PubMed]

26. Rickels, K.; Schweizer, E.; Case, W.G.; Greenblatt, D.J. Long-term therapeutic use of benzodiazepines. I. Effects of abrupt discontinuation. Arch. Gen. Psychiatry 1990, 47, 899-907. [CrossRef] [PubMed]

27. Neutel, C.I. Risk of traffic accident injury after a prescription for a benzodiazepine. Ann. Epidemiol. 1995, 5, 239-244. [CrossRef]

28. Neutel, C.I.; Perry, S.; Maxwell, C. Medication use and risk of falls. Pharmacoepidemiol. Drug Saf. 2002, 11, 97-104. [CrossRef] [PubMed]

29. Paterniti, S.; Dufouil, C.; Alperovitch, A. Long-term benzodiazepine use and cognitive decline in the elderly: The Epidemiology of Vascular Aging Study. J. Clin. Psychopharmacol. 2002, 22, 285-293. [CrossRef] [PubMed]

30. Holm, K.J.; Goa, K.L. Zolpidem: An update of its pharmacology, therapeutic efficacy and tolerability in the treatment of insomnia. Drugs 2000, 59, 865-889. [CrossRef] [PubMed]

31. Hoffmann, F.; Hies, M.; Glaeske, G. Regional variations of private prescriptions for the non-benzodiazepine hypnotics zolpidem and zopiclone in Germany. Pharmacoepidemiol. Drug Saf. 2010, 19, 1071-1077. [CrossRef] [PubMed]

32. Victorri-Vigneau, C.; Dailly, E.; Veyrac, G.; Jolliet, P. Evidence of zolpidem abuse and dependence: Results of the French Centre for Evaluation and Information on Pharmacodependence (CEIP) network survey. Br. J. Clin. Pharmacol. 2007, 64, 198-209. [CrossRef] [PubMed]

33. Rudisill, T.M.; Zhu, M.; Kelley, G.A.; Pilkerton, C.; Rudisill, B.R. Medication use and the risk of motor vehicle collisions among licensed drivers: A systematic review. Accid. Anal. Prev. 2016, 96, 255-270. [CrossRef] [PubMed]

34. Booth, J.N.; Behring, M.; Cantor, R.S.; Colantonio, L.D.; Davidson, S.; Donnelly, J.P.; Johnson, E.; Jordan, K.; Singleton, C.; Xie, F.; et al. Zolpidem use and motor vehicle collisions in older drivers. Sleep Med. 2016, 20, 98-102. [CrossRef] [PubMed]

35. James, S.P.; Mendelson, W.B. The use of trazodone as a hypnotic: A critical review. J. Clin. Psychiatry 2004, 65, 752-755. [CrossRef]

36. Bossini, L.; Casolaro, I.; Koukouna, D.; Cecchini, F.; Fagiolini, A. Off-label uses of trazodone: A review. Expert Opin. Pharmacother. 2012, 13, 1707-1717. [CrossRef] [PubMed]

37. Su, T.P.; Chen, T.J.; Hwang, S.J.; Chou, L.F.; Fan, A.P.; Chen, Y.C. Utilization of psychotropic drugs in Taiwan: An overview of outpatient sector in 2000. Zhonghua Yi Xue Za Zhi (Taipei) 2002, 65, 378-391. [PubMed]

38. Santamaría, B.; Pérez, M.; Montero, D.; Madurga, M.; de Abajo, F.J. Use of antipsychotic agents in Spain through 1985-2000. Eur. Psychiatry 2002, 17, 471-476. [CrossRef]

39. Bret, P.; Bret, M.C.; Queuille, E. Prescribing patterns of antipsychotics in 13 French psychiatric hospitals. Encephale 2008, 35, 129-138. [CrossRef] [PubMed]

40. Rojo, L.E.; Gaspar, P.A.; Silva, H.; Risco, L.; Arena, P.; Cubillos-Robles, K.; Jara, B. Metabolic syndrome and obesity among users of second generation antipsychotics: A global challenge for modern psychopharmacology. Pharmacol. Res. 2015, 101, 74-85. [CrossRef] [PubMed]

41. Mojtabai, R.; Olfson, M. National trends in long-term use of antidepressant medications: Results from the U.S. National Health and Nutrition Examination Survey. J. Clin. Psychiatry 2014, 75, 169-177. [CrossRef] [PubMed]

42. Wolfsperger, M.; Greil, W.; Rössler, W.; Grohmann, R. Pharmacological treatment of acute mania in psychiatric in-patients between 1994 and 2004. J. Affect. Disord. 2007, 99, 9-17. [CrossRef] [PubMed] 
43. Bowden, C.L. Key treatment studies of lithium in manic-depressive illness: Efficacy and side effects. J. Clin. Psychiatry 1998, 59, 13-19.

44. Zajecka, J.M.; Weisler, R.; Sachs, G.; Swann, A.C.; Wozniak, P.; Sommerville, K.W. A comparison of the efficacy, safety, and tolerability of divalproex sodium and olanzapine in the treatment of bipolar disorder. J. Clin. Psychiatry 2002, 63, 1148-1155. [CrossRef]

45. Osborn, D.P.; Wright, C.A.; Levy, G.; King, M.B.; Deo, R.; Nazareth, I. Relative risk of diabetes, dyslipidaemia, hypertension and the metabolic syndrome in people with severe mental illnesses: Systematic review and metaanalysis. BMC Psychiatry 2008, 8, 84. [CrossRef] [PubMed]

46. Chien, I.C.; Hsu, J.H.; Lin, C.H.; Bih, S.H.; Chou, Y.J.; Chou, P. Prevalence of diabetes in patients with schizophrenia in Taiwan: A population-based National Health Insurance study. Schizophr. Res. 2009, 111, 17-22. [CrossRef] [PubMed]

47. Liao, C.H.; Chang, C.S.; Wei, W.C.; Chang, S.N.; Liao, C.C.; Lane, H.Y.; Sung, F.C. Schizophrenia patients at higher risk of diabetes, hypertension and hyperlipidemia: A population-based study. Schizophr. Res. 2011, 126, 110-116. [CrossRef] [PubMed]

48. Nehra, V.; Bruce, B.K.; Rath-Harvey, D.M.; Pemberton, J.H.; Camilleri, M. Psychological disorders in patients with evacuation disorders and constipation in a tertiary practice. Am. J. Gastroenterol. 2000, 95, 1755-1758. [CrossRef] [PubMed]

49. Jessurun, J.G.; van Harten, P.N.; Egberts, T.C.; Pijl, B.J.; Wilting, I.; Tenback, D.E. The effect of psychotropic medications on the occurrence of constipation in hospitalized psychiatric patients. J. Clin. Psychopharmacol. 2013, 33, 587-590. [CrossRef] [PubMed]

50. Wang, P.S.; Lane, M.; Olfson, M.; Pincus, H.A.; Wells, K.B.; Kessler, R.C. Twelve-month use of mental health services in the United States: Results from the National Comorbidity Survey Replication. Arch. Gen. Psychiatry 2005, 62, 629-640. [CrossRef] [PubMed]

(C) 2016 by the authors; licensee MDPI, Basel, Switzerland. This article is an open access article distributed under the terms and conditions of the Creative Commons Attribution (CC-BY) license (http://creativecommons.org/licenses/by/4.0/). 